\title{
Comparison of expressed human and mouse sodium/iodide symporters reveals differences in transport properties and subcellular localization
}

\author{
Manal Dayem*, Cécile Basquin*, Valérie Navarro, Patricia Carrier, Robert Marsault, Patrick Chang ${ }^{1}$, \\ Sylvaine Huc ${ }^{2}$, Elisabeth Darrouzet ${ }^{2}$, Sabine Lindenthal and Thierry Pourcher \\ TIRO, CEA DSV-iBEB-SBTN, CAL, School of Medicine, University of Nice Sophia Antipolis, 28 Avenue de Valombrose, 06107, Nice, France \\ ${ }^{1}$ UMR7009 CNRS/UPMC Biologie du Développement, 06230 Villefranche-sur-Mer, France \\ ${ }^{2}$ CEA Center of Valrhô, DSV-iBEB-SBTN, 30207 Bagnols-sur-Cèze, France \\ (Correspondence should be addressed to T Pourcher; Email: pourcher@unice.fr) \\ *(M Dayem and C Basquin contributed equally to this work)
}

\begin{abstract}
The active transport of iodide from the bloodstream into thyroid follicular cells is mediated by the $\mathrm{Na}^{+} / \mathrm{I}^{-}$symporter (NIS). We studied mouse NIS (mNIS) and found that it catalyzes iodide transport into transfected cells more efficiently than human NIS (hNIS). To further characterize this difference, we compared ${ }^{125} \mathrm{I}$ uptake in the transiently transfected human embryonic kidney (HEK) 293 cells. We found that the $V_{\max }$ for mNIS was four times higher than that for hNIS, and that the iodide transport constant $\left(K_{\mathrm{m}}\right)$ was $2 \cdot 5$-fold lower for hNIS than mNIS. We also performed immunocytolocalization studies and observed that the subcellular distribution of the two orthologs differed. While the mouse protein was predominantly found at the plasma membrane, its human ortholog was intracellular in $~ 40 \%$ of the expressing cells. Using cell surface protein-labeling assays,
\end{abstract}

we found that the plasma membrane localization frequency of the mouse protein was only $2 \cdot 5$-fold higher than that of the human protein, and therefore cannot alone account for the difference in the obtained $V_{\max }$ values. We reasoned that the observed difference could also be caused by a higher turnover number for iodide transport in the mouse protein. We then expressed and analyzed chimeric proteins. The data obtained with these constructs suggest that the iodide recognition site could be located in the region extending from the $\mathrm{N}$-terminus to transmembrane domain 8 , and that the region between transmembrane domain 5 and the C-terminus could play a role in the subcellular localization of the protein.

Journal of Endocrinology (2008) 197, 95-109

\section{Introduction}

The transport and concentration of iodide from the blood by the thyroid gland is a prerequisite for thyroid hormone synthesis. The key player in this process is the sodium/ iodide symporter (NIS, for natrium iodide symporter). The rat NIS sequence was the first to be identified (Dai et al. 1996), followed by the human (Smanik et al. 1996) and mouse sequences (Perron et al. 2001). The human and rat/ mouse proteins are 643 and 618 amino acids in length respectively. NIS, also named as solute linked carrier 5A5 (SLC5A5), is a member of the sodium/solute symporter family, and is an integral membrane protein that resides in the basolateral membrane of thyroid epithelial cells (for review see Dohan et al. (2003)). Predicted and experimental data suggest that the NIS protein is organized into 13 membrane-spanning domains (Dohan \& Carrasco 2003). Although the NIS contains N-linked carbohydrates, these modifications are apparently not required for full transport activity (Levy et al. 1998b). The NIS transports both $\mathrm{Na}^{+}$ and $\mathrm{I}^{-}$ions from the extracellular fluid (i.e., the blood) into thyroid follicular cells. The stoichiometry of the cotransport is two sodium ions for one iodide ion, with energy provided by the electrochemical gradient of sodium across the plasma membrane. Once in the cell, the iodide is translocated across the apical membrane into the lumen, where it is immediately organified as thyroglobulin, i.e., the thyroid hormone precursor. Through this mechanism, iodide becomes concentrated in the thyroid gland at 20- to 40-fold higher levels than in the plasma.

The NIS-mediated iodide accumulation that occurs in thyrocytes is a useful tool for the diagnosis and treatment of thyroid diseases. The NIS allows the diagnosis of thyroid dysfunction via scintigraphic imaging, and thyroid cancer can be treated using radioiodide therapy. The cloning of the NIS cDNA has opened the door to a new gene therapy strategy for 
the treatment of cancer cells. In a series of preclinical trials, the NIS gene was successfully transduced into various cancer cell types. NIS expression then catalyzed radioiodide uptake, resulting in targeted cell destruction. However, more detailed knowledge of the NIS protein is still needed to obtain improved iodide accumulation and facilitate future therapeutic strategies.

To date, the importance of individual amino acids and protein domains within the NIS for the protein's function is only partially understood. Mutations in the NIS gene leading to iodide transport defects and congenital hypothyroidism have been reported (Pohlenz \& Refetoff 1999, Dohan et al. 2003, Szinnai et al. 2006). Certain residues that could be important for transport activity have been studied at the molecular level by site-directed mutagenesis: a hydroxyl group at residue 354 appears to be essential for NIS function (Levy et al. 1998a); a charged or large side chain at position 395 interferes with the NIS transport activity (Dohan et al. 2002); charged residues other than Glu at position 267 render NIS inactive (De La Vieja et al. 2004); and the G543 residue seems to be important for the localization of NIS to the plasma membrane (De la Vieja et al. 2005). However, further in vitro studies are required to better understand the molecular mechanisms of sodiumcoupled iodide transport.

Heltemes et al. (2003) reported that the rat NIS protein is more efficient than the human protein for radioisotope concentration. More recently, Mitrofanova et al. (2006) compared the human and rat NIS genes for their efficacy in cancer therapy. The authors demonstrated that the rat NIS allows the administration of lower doses of ${ }^{131}$ I to arrest the growth of tumor xenografts in mice. The observed differences in the iodine-concentrating ability, and thus the therapeutic efficacy, between the two orthologs may reflect differences in cell surface targeting. Indeed, Zhang et al. (2005) have shown that although the rat and human NIS proteins are expressed at equivalent levels, only the rat NIS is present at the plasma membrane, with the human protein being found predominantly within cells. They have also analyzed rat/human NIS chimeras and concluded that multiple regions play a role in NIS subcellular localization and that the protein's tertiary structure is critical for surface targeting.

Better understanding of the molecular mechanisms involved in the iodine transport capacity and the posttranscriptional regulation and targeting of the NIS protein should be useful for the development of NIS-based clinical applications, in particular for the imaging of tumor cells and targeted radiotherapy. For this purpose, we analyzed the transport properties and subcellular distribution of the human and mouse (the closest ortholog of the rat gene) NIS transiently expressed in human embryonic kidney (HEK) 293 cells. Our data provide insight into the differences in transport behavior and subcellular distribution of the human NIS compared with its rat/mouse counterparts.

\section{Materials and Methods}

Mutagenesis, plasmids, and cDNA construction of His-tagged and chimeric NIS

The mouse NIS (mNIS) coding region was subcloned into pcDNA3.1 (Invitrogen) as described previously (Perron et al. 2001). The full-length human NIS ( $h N I S$; a generous gift of Prof. S M Jhiang) was inserted between the BamHI and XhoI sites of the pcDNA5 FRT plasmid (Invitrogen). In both constructs, the $5^{\prime}$-non-coding region of the cDNA was removed and a Kozak (1997) consensus sequence introduced before the initiator ATG. This sequence, including the NotI restriction site used for the subcloning, was GCGGCCGCCACCATG for mNIS. For hNIS, the sequence, including the BamHI restriction site used for subcloning, was GGATCCGCACCATG. The constructs carrying the mNIS sequence without a histidine tag contained 33 bases from the $3^{\prime}$-non-coding region downstream of the stop codon. The constructs carrying the hNIS sequence without a histidine tag contained 92 bases from the $3^{\prime}$-noncoding region. These non-coding regions were removed in the constructs encoding the His-tagged proteins. The cDNA constructs encoding the His-tagged proteins were engineered by inserting the sequence CATCATCACCATCACCAT (which codes for six histidine residues) at the $3^{\prime}$ extremity of the cDNAs by PCR using Pwo polymerase and appropriate primers (Genosys, Cambridge, UK). Chimeric transporters were produced by exchanging the C-terminal extremities of the human and mouse NIS proteins. The chimeric cDNAs were produced according to a previously described method involving swapping sites (Katagiri et al. 1992). Overlapping segments corresponded to conserved regions. The primer sequences for the chimeras were: 1 ) between helices 4 and 5 , 5'-ACATCTGGGCGTCGCTCCTGTCCACCG-3' (sense strand) and 5'-CGGTGGACAGGAGCGACGCCCAGAT$3^{\prime}$ (antisense strand); 2) between helices 8 and 9, 5'-TTCC TGGCCTGTGCTTACAGTGGCA- $3^{\prime}$ (sense strand) and 5'-TGCCACTGTAAGCACAGGCCAGGAA-3' (antisense strand); 3) between transmembrane domain 13 and the C-terminus, $5^{\prime}$-CTGACAGGCCCCACCAAGCGCA-3' (sense strand) and $5^{\prime}$-GCTGCGCTTGGTGGGGCCTG TCAG-3' (antisense strand). These overlapping segments encoded the conserved sequences DIWASLLSTG (starting at transmembrane domain 5), FLACAYSG (starting at transmembrane domain 9), and LTGPTKRS (following transmembrane domain 13). The final PCR products were hydrolyzed and inserted into the mouse NIS pcDNA3.1 and the human NIS pcDNA5 plasmids. All PCR-amplified portions were sequenced.

\section{Antibodies}

Antibody 25 (Ab 25 anti-mNIS) is an affinity-purified fraction of a rabbit immunoreactive serum. Two peptide sequences in the $\mathrm{C}$-terminus of the mNIS were selected using the double XP 
program from Eurogentec (Seraing, Belgium) and synthesized. The synthetic peptides, CAETHPLYLGHDVETNL (comprising amino acids 603-618) and CVEDLIKPRMPSLAPR (comprising amino acids 367-381), were conjugated to the carrier molecule hemocyanin. Immunoreactive sera were obtained by multipoint injections of a mixture of both peptides. A peptide corresponding in sequence to amino acids 603-618 was coupled to a sepharose gel and used to purify the antibody. The primary monoclonal anti-human NIS antibody $39 \mathrm{~S}$ (Ab 39S anti-hNIS) was obtained by injecting mice with purified NIS protein. Characterization of this antibody indicated that it predominantly recognizes a domain in the cytoplasmic C-terminal portion of the protein comprising amino acids 580-600 (article in preparation). Purified mouse monoclonal anti-His-tag antibody was purchased from Qiagen (QIAexpress anti-His antibodies). All primary antibodies were used at a 1:3000 dilution in PBS with $2 \mathrm{~g} / 1$ casein (I-Block; Tropix, Bedford, MA, USA) for western blotting, and at 1:200 in PBS with 1\% BSA for immunofluorescence experiments. For western blots, secondary goat anti-mouse or goat anti-rabbit antibodies coupled to horseradish peroxidase (HRP) were obtained from Pierce (Immunopure antibodies, Pierce-Perbio, Brebières, France). Tetramethylrhodamine isothiocyanate (TRITC)-conjugated secondary antibodies used for immunocytochemistry were purchased from Sigma. Secondary antibodies were used at a dilution of 1:5000 in PBS-casein $(2 \mathrm{~g} / \mathrm{l})$ for western blots and at 1:250 in PBS-BSA (1\%) for immunofluorescence.

\section{Cell culture}

HEK 293 cells were grown in Dulbecco's modified Eagle's medium (DMEM) supplemented with 10\% fetal calf serum, $10 \mathrm{mM}$ L-glutamine, and $0.01 \mathrm{mg} / \mathrm{ml}$ gentamicin, at $37^{\circ} \mathrm{C}$ in a humidified $5 \% \mathrm{CO}_{2}$ atmosphere (all cell culture media, supplements, and reagents were obtained from Invitrogen).

\section{Transfections}

HEK cells were seeded the day before transfection onto plates coated with $10 \mathrm{mg} / \mathrm{ml}$ poly-L-lysine (Sigma-Aldrich) at a density of $3 \times 10^{6}$ cells $/ 75 \mathrm{~cm}^{2}$. In general, transfection was performed the following day at $\sim 60 \%$ cell confluence ( $40 \%$ for immunocytochemistry), using the FuGENE 6 reagent (Roche) according to the manufacturer's protocol. For each experiment, the transfection efficiency was estimated using an immunofluorescence assay (see below). Usually, between 60 and $70 \%$ of the total cells expressed the NIS proteins. Sets of experiments that did not show such transfection efficiencies were not used.

\section{Iodide uptake assays, $\mathrm{K}_{m}$, and $\mathrm{V}_{\max }$ measurements}

Iodide uptake assays were performed 2 days after transfection. Monolayers of confluent, transiently transfected HEK 293 cells were washed with Hank's buffered salt solution (HBSS) $/ 10 \mathrm{mM}$ HEPES buffer and incubated in buffer containing $30 \mu \mathrm{M} \mathrm{Na}{ }^{125} \mathrm{I}(50 \mathrm{Ci} / \mathrm{mol})$ at $37^{\circ} \mathrm{C}$. Iodide uptake was stopped by adding ice-cold HBSS $/ 10 \mathrm{mM}$ HEPES buffer, followed by two washes in the same ice-cold buffer. The cells were then permeabilized in ethanol and the radioactivity measured using a $\gamma$-counter (Packard). For kinetic analysis, the cells were incubated with buffer containing different concentrations of $\mathrm{NaI}$ (in $\mu \mathrm{M}: 2 \cdot 5,5$, $7 \cdot 5,10,15,20,30,40,60,80,120,160)$ for $4 \mathrm{~min}$. For each experiment, the background (experiment in the presence of perchlorate) has been subtracted. For iodide uptake assays (as with the immunoblot, immunofluorescence, and cell surface biotinylation experiments shown in this study), each set of experiments (cells transfected with plasmids encoding the different NIS orthologs or chimeras) was performed at the same time, using the same conditions, and starting from the same batch of cells. All results shown are the average of at least three different experiments, each performed in triplicate.

\section{$\mathrm{K}_{m \mathrm{Na}}$ measurements}

Sodium was replaced by tetramethyl ammonium chloride (TMA; Sigma-Aldrich). NIS-transfected HEK cells were washed with a sodium-free washing buffer (10 mM HEPES, $2 \mathrm{mM} \mathrm{KCl}, 1 \mathrm{mM} \mathrm{CaCl}_{2}, 1 \mathrm{mM} \mathrm{MgCl}, 160 \mathrm{mM} \mathrm{TMA}$ ) and then incubated in buffer containing different $\mathrm{NaCl}$ concentrations (in mM: $2 \cdot 5,5,7 \cdot 5,10,15,20,30,40,60,80,120,160$ ) for $4 \mathrm{~min}$. The different $\mathrm{NaCl}$ concentrations were obtained by mixing a dilution buffer $(10 \mathrm{mM}$ HEPES, $2 \mathrm{mM} \mathrm{KCl}, 1 \mathrm{mM}$ $\mathrm{CaCl}_{2}, 1 \mathrm{mM} \mathrm{MgCl} 2,160 \mathrm{mM}$ TMA, $30 \mu \mathrm{M} \mathrm{NaI}$ ) with a sodium-containing buffer $(10 \mathrm{mM} \mathrm{HEPES}, 2 \mathrm{mM} \mathrm{KCl}, 1 \mathrm{mM}$ $\mathrm{CaCl}_{2}, 1 \mathrm{mM} \mathrm{MgCl}_{2}, 160 \mathrm{mM} \mathrm{NaCl}, 30 \mu \mathrm{M} \mathrm{NaI}$ ) in appropriate ratios. After incubation, three washes were performed with the washing buffer. Cells were then permeabilized in ethanol and the radioactivity measured with a $\gamma$-counter.

\section{SDS-PAGE and immunoblot analysis}

All samples were diluted 1:5 with loading buffer containing $0.3 \mathrm{M}$ Tris ( $\mathrm{pH} 6.8$ ), $0.5 \mathrm{M}$ dithiothreitol (DTT), and $50 \%$ glycerol. The samples were then incubated at $42{ }^{\circ} \mathrm{C}$ for $45 \mathrm{~min}$, before PAGE. Equal amounts of protein $(10 \mu \mathrm{g})$ were separated on SDS-10\% PAGE and transferred to a polyvinylidene difluoride (PVDF) membrane (Hybond-ECL; GE healthcare, Orsay, France). Membranes were saturated for $45 \mathrm{~min}$ in blocking buffer (PBS, $2 \mathrm{~g} / \mathrm{l}$ casein from I-Block; Tropix) and then incubated for $2 \mathrm{~h}$ at room temperature with the primary antibody. Subsequently, the membranes were washed three times for $10 \mathrm{~min}$ in $1 \times$ PBS buffer and incubated with the secondary antibody for $45 \mathrm{~min}$ at room temperature. Three final washes in $1 \times$ PBS buffer were performed, $10 \mathrm{~min}$ each. Results were revealed with an enhanced chemiluminescence detection system (Amersham ECL plus, GE healthcare). For control experiments with housekeeping proteins, the membrane was stripped in $62 \mathrm{mM}$ Tris ( $\mathrm{pH} \mathrm{6 \cdot 7)}, 100 \mathrm{mM}$ 2-mercaptoethanol, and 2\% SDS. After several washes (in PBS), the membrane was incubated with tubulin-specific monoclonal antibodies (clone 
D66, $1 \cdot 1 \mu \mathrm{g} / \mathrm{ml}$; Sigma-Aldrich). Quantification of western blot experiments was performed on images scanned from autoradiographic films using ImageQuant software (GE Healthcare).

\section{Immunofluorescence}

HEK 293 cells were seeded onto poly-L-lysine pre-coated coverslips the day before transfection. Forty-eight hours after transfection, when cells reached $40-50 \%$ confluence, they were rinsed three times with $1 \times$ PBS buffer at room temperature and then fixed in $10 \%$ paraformaldehyde $/ 0 \cdot 02 \%$ glutaraldehyde/1 X PBS (Chang et al. 1996) for $15 \mathrm{~min}$. The cells were permeabilized by briefly rinsing the coverslips in $100 \%$ methanol $\left(-20{ }^{\circ} \mathrm{C}\right)$ and then washed three times for $5 \mathrm{~min}$ in $50 \mathrm{mM} \mathrm{NH}_{4} \mathrm{Cl} / 1 \times$ PBS. Again, the cells were permeabilized for $30 \mathrm{~s}$ in $0.01 \%$ Triton X-100/1\% methanol in $1 \times$ PBS. Three washes of 5 min each were performed in $1 \times$ PBS. The cells were then blocked for $30 \mathrm{~min}$ in $1 \times \mathrm{PBS} / 1 \% \mathrm{BSA}$. Primary antibodies were diluted 1:250 in PBS/0.1\% BSA and incubation carried out overnight at $4{ }^{\circ} \mathrm{C}$. After three washes, $10 \mathrm{~min}$ each, in $1 \times \mathrm{PBS}$, the cells were incubated with $200 \mu \mathrm{l}$ $1 \times \mathrm{PBS} / 0 \cdot 1 \%$ BSA containing a TRITC-conjugated antirabbit or anti-mouse secondary antibody (dilution 1:350, Sigma-Aldrich). After $1-\mathrm{h}$ incubation in the dark at room temperature, the coverslips were washed three times for $5 \mathrm{~min}$ in $1 \times$ PBS and mounted onto microscope slides using Gel Mount (Interchim, Montluçon, France).

Image acquisition was performed using a Zeiss Axiovert 200M microscope equipped with a CoolSNAP CCD camera from Photometric and the METAView program (Roper Scientific, Evry, France). When required, deconvolution of the images was performed using AutoQuant X1.33 software (AutoQuant Imaging Inc, Bethesda, MD, USA).

\section{Statistical study of NIS protein localization}

Six coverslips were prepared for each experimental condition and 50 different images were acquired per coverslip. All stained cells were counted taking into account the subcellular localization of the labeling. The labeled cells were counted from images visualized with a computer. The counting was repeated by different researchers to verify the accuracy of the measurements.

\section{Cell surface biotinylation}

HEK 293 cells were seeded onto $100 \mathrm{~mm}$ tissue culture dishes (Corning, Schiphol-Rijk, The Netherlands) coated with poly-L-lysine (Sigma-Aldrich) and transfected the following day. Forty-eight hours after transfection, the cells were washed two times with ice-cold PBS containing $0.1 \mathrm{mM}$ $\mathrm{CaCl}_{2}, 1 \mathrm{mM} \mathrm{MgCl}_{2}, 138 \mathrm{mM} \mathrm{NaCl}, 2 \cdot 7 \mathrm{mM} \mathrm{KCl}, 9 \cdot 6 \mathrm{mM}$ $\mathrm{Na}_{2} \mathrm{HPO}_{4}, 15 \mathrm{mM} \mathrm{KH}{ }_{2} \mathrm{PO}_{4}(\mathrm{pH} 8$; biotinylation washing buffer). The cells were then incubated for $30 \mathrm{~min}$ at $4{ }^{\circ} \mathrm{C}$ in biotinylation washing buffer supplemented with $1 \mathrm{mg} / \mathrm{ml}$ sulfosuccinimidyl-2-(biotinamido)ethyl-1,3-dithiopropionate
(Sulfo-NHS-SS-biotin; Pierce, EZ-Link Sulfo-NHSSS-Biotin). Remaining free Sulfo-NHS-SS-biotin was removed by washing three times in ice-cold biotinylation washing buffer containing $100 \mathrm{mM}$ glycine at $4{ }^{\circ} \mathrm{C}$. The cells were then lysed in lysis buffer $(0 \cdot 1 \% \mathrm{SDS} / 1 \%$ Triton $\mathrm{X}-100 / 1 \%$ sodium deoxycholate/150 mM NaCl/1 mM EDTA $/ 100 \mathrm{mM}$ Tris-HCl $(\mathrm{pH} \quad 7 \cdot 5) / 1 \mu \mathrm{g} / \mathrm{ml}$ aproti$\mathrm{nin} / 1 \mu \mathrm{g} / \mathrm{ml}$ leupeptin) for $15 \mathrm{~min}$ at $4{ }^{\circ} \mathrm{C}$ with continuous shaking. The lysates were centrifuged for $15 \mathrm{~min}$ at $10000 \mathrm{~g}$. The supernatant was designated 'total cellular extract fraction' (TCEF). Two hundred microliters of TCEF were kept for protein quantification and immunoblotting. Hundred microliters of streptavidin-agarose beads (Immunopure Immobilized Streptavidin, Pierce) were added to the remaining TCEF and incubated for $1 \mathrm{~h}$ at room temperature with constant gentle rotational shaking. The suspension was then centrifuged for $5 \mathrm{~min}$ at $10000 \mathrm{~g}$. The pelleted beads were washed three times in $500 \mu \mathrm{l}$ lysis buffer, and bound proteins were released through the addition of $200 \mu \mathrm{l} 2 \times$ elution buffer (Tris $60 \mathrm{mM} \quad(\mathrm{pH} \quad 6 \cdot 8) / 2 \% \quad \mathrm{SDS} / 10 \%$ glycerol/1\% $\beta$-mercaptoethanol/0.1\% bromophenol blue). Protein concentrations were determined using the Bradford assay, and SDS-PAGE was carried out as described above. Quantification of western blot experiments was performed on images scanned from autoradiographic films using the ImageQuant software (GE Healthcare). For control experiments with housekeeping proteins, the membranes were stripped in $62 \mathrm{mM}$ Tris (pH 6.7), $100 \mathrm{mM}$ 2 -mercaptoethanol, and 2\% SDS. After several washes (in $\mathrm{PBS}$ ), the membranes were incubated with $\mathrm{Na} / \mathrm{K}$ ATPasespecific monoclonal antibodies (clone 464 6 , dilution 1:5000; Novus Biologicals, Littleton, CO, USA).

\section{Statistical analysis}

S.E.M. were calculated using Microsoft Excel software for all experiments. Student's $t$-tests were also performed using Excel.

\section{Results}

$m$ NIS iodide uptake is $60 \%$ higher than hNIS iodide uptake

HEK 293 cells transiently transfected with recombinant pcDNA vectors encoding the wild-type human or mouse NIS showed significant iodide accumulation, and, in both cases, the kinetics of iodide transport began to plateau after $30 \mathrm{~min}$ of incubation with $30 \mu \mathrm{M} \mathrm{NaI}$ (Fig. 1A). We found that hNIS was less efficient than mNIS in iodide uptake activity (Fig. 1A). In Fig. 1A, the iodide uptake in the hNIS- and mNIS-expressing HEK 293 cells is expressed as a percentage of the iodide uptake in mNISexpressing HEK 293 cells after $30 \mathrm{~min}$ (set at 100\%). Averaging several experiments revealed that the value of the iodide uptake for hNIS-expressing cells after $30 \mathrm{~min}$ was 38\% that for mNIS-expressing cells (Table 1). This accumulation that could be inhibited with $100 \mu \mathrm{M}$ of the competitive NIS 

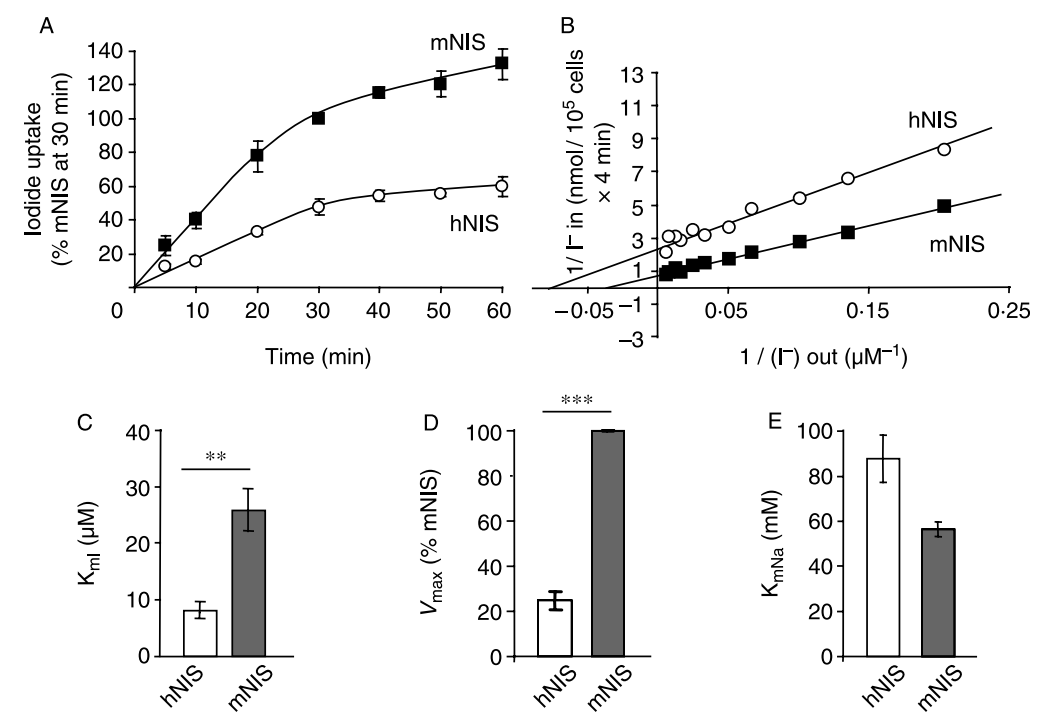

Figure 1 Kinetic properties of hNIS and mNIS transiently expressed in HEK 293 cells. (A) ${ }^{125}$ I Uptake experiments: cells were incubated in $30 \mu \mathrm{M} \mathrm{Nal}$ containing $0 \cdot 1 \mathrm{mCi}$ ${ }^{125} \mathrm{I}$, for the indicated times, washed, and the accumulated iodide was measured after permeabilization with ethanol using a $\gamma$-counter. These experiments are representative of five different experiments, each performed in triplicate, and are expressed as a percentage of the $\mathrm{mNIS}$ iodide accumulation (set at 100\%) after $30 \mathrm{~min}$ of incubation. (B) Kinetic analysis of the iodide uptake: the Lineweaver-Burk representation is illustrated with one representative experiment. (C) Calculated $K_{\mathrm{ml}}$ values.

(D) Calculated hNIS $V_{\max }$ values, expressed as a percentage of $\mathrm{mNIS}$ (set at $100 \%$ ).

(E) Calculated $K_{\mathrm{m}}$ values for $\mathrm{Na}^{+}$. (D and E) The results are representative of four independent experiments, each performed in triplicate. ${ }^{* * *} P<0 \cdot 0005 .{ }^{* *} P<0 \cdot 002$.

inhibitor perchlorate (data not shown) was not observed in non-transfected cells. Data for each experiment are presented as percentages of the values obtained with mNIS-expressing cells at $30 \mathrm{~min}$ in order to normalize the different sets of experiments. Small differences were found between experiments and are related to minor variations in the different batches of cells, the amount of cells per well, and the transfection efficiencies. Potential differences in transfection efficiencies were analyzed using immunocytochemistry assays that were carried out simultaneously for the uptake experiments, using the same batch of cells and the same conditions. No differences were observed in transfection efficiency between the hNIS- and mNIS-encoding plasmids.

\section{hNIS has a higher affinity than $m$ NIS for iodide}

In order to understand the molecular mechanisms underlying the observed difference in the uptake activity between hNIS and mNIS, the kinetic properties of iodide uptake in the HEK 293 cells transiently expressing hNIS or mNIS were analyzed.

Table 1 Kinetic and transport properties of wild-type, chimeric, and histidine-tagged natrium iodide symporter (NIS) proteins

\begin{tabular}{|c|c|c|c|c|}
\hline & $\begin{array}{l}\text { Uptake mean } \\
\qquad n=3(\% \mathrm{mNIS})\end{array}$ & $\begin{array}{c}\boldsymbol{K}_{\mathbf{m} \mathbf{l}} \text { mean } \\
n=4(\mu \mathrm{M})\end{array}$ & $\begin{array}{l}\boldsymbol{V}_{\max } \text { mean } \\
n=4(\% \mathrm{mNIS})\end{array}$ & $\begin{array}{c}K_{\mathrm{mNa}} \text { mean } \\
n=5(\mathrm{mM})\end{array}$ \\
\hline hNIS & $38 \cdot 2 \pm 7 \cdot 1$ & $9 \cdot 0 \pm 0 \cdot 8$ & $24 \cdot 7 \pm 4 \cdot 1$ & $81 \cdot 6 \pm 8 \cdot 1$ \\
\hline hNISH & $39 \cdot 3 \pm 3 \cdot 0$ & $8 \cdot 4 \pm 1 \cdot 0$ & $24 \cdot 5 \pm 5 \cdot 1$ & $92 \cdot 6 \pm 12 \cdot 8$ \\
\hline $\mathrm{mNISH}$ & $85 \cdot 1 \pm 7 \cdot 0$ & $24 \cdot 6 \pm 1 \cdot 9$ & $83 \cdot 7 \pm 3 \cdot 9$ & $59 \cdot 6 \pm 8 \cdot 3$ \\
\hline hNISmCter & $46 \cdot 4 \pm 4 \cdot 4$ & $9 \cdot 7 \pm 2 \cdot 5$ & $21 \cdot 9 \pm 5 \cdot 7$ & $74 \cdot 1 \pm 3 \cdot 5^{*}$ \\
\hline mNIShCterH & $72 \cdot 6 \pm 6 \cdot 3$ & $21 \cdot 0 \pm 1 \cdot 5$ & $71 \cdot 0 \pm 4 \cdot 0$ & - \\
\hline h4m9 & $81 \cdot 4 \pm 8 \cdot 5$ & $40 \cdot 2 \pm 3 \cdot 2$ & $66 \cdot 7 \pm 3 \cdot 6$ & $82 \cdot 2 \pm 2 \cdot 0^{*}$ \\
\hline m4h9 & $43 \cdot 3 \pm 0 \cdot 1$ & $25 \cdot 8 \pm 1 \cdot 8$ & $46 \cdot 2 \pm 5 \cdot 0$ & $65 \cdot 6 \pm 2 \cdot 7^{*}$ \\
\hline h8m5 & $65 \cdot 5 \pm 9 \cdot 8$ & $20 \cdot 7 \pm 0 \cdot 7$ & $42 \cdot 6 \pm 0 \cdot 8$ & $58 \cdot 2 \pm 3 \cdot 8^{*}$ \\
\hline m8h5 & $46 \cdot 9 \pm 2 \cdot 3$ & $28 \cdot 5 \pm 0 \cdot 2$ & $39 \cdot 6 \pm 2 \cdot 4$ & $79 \cdot 3 \pm 0 \cdot 9 *$ \\
\hline
\end{tabular}

$\left({ }^{*} n=2\right)$. 
We first measured the effects of varying concentrations of $\mathrm{I}^{-}$ (ranging from $0 \cdot 25$ to $160 \mu \mathrm{M}$ ) on the initial rates of $\mathrm{I}^{-}$ transport (at 4 min; Fig. 1B). The calculated mean $K_{\mathrm{mI}}$ values for hNIS and mNIS were $9 \pm 0 \cdot 8 \mu \mathrm{M}$ and $26 \cdot 4 \pm 3 \cdot 5 \mu \mathrm{M}$ respectively (Fig. 1C; Table 1). The iodide transport constant of the mouse protein was three times that of the human protein, suggesting that $\mathrm{mNIS}$ has a lower iodide affinity than hNIS. Thus, the observed difference in iodide uptake (using $30 \mu \mathrm{M}$ iodide) between hNIS and mNIS cannot be explained by their different iodide transport constants. The corresponding $V_{\max }$ for hNIS-expressing cells was expressed as a percentage of that for mNIS-expressing cells (set at 100\%), and showed a value of about 25\% (Fig. 1D; Table 1). These $V_{\max }$ values are also shown as percentages in order to normalize the different sets of experiments.

\section{$m$ NIS has a higher affinity than $h N I S$ for $\mathrm{Na}^{+}$}

The kinetic properties of $\mathrm{Na}^{+}$-dependent iodide uptake in the hNIS- and mNIS-expressing HEK 293 cells were investigated. The $K_{\mathrm{mNa}}$ values for hNIS and mNIS were $81.6 \pm 8 \cdot 1 \mathrm{mM}$ and $59 \cdot 4 \pm 4 \cdot 0 \mathrm{mM}$ respectively (Fig. 1E; Table 1 ). Considering the sodium concentration of $\sim 160 \mathrm{mM}$ in the buffer (HBSS) used for the uptake assays, the observed iodide uptake differences between hNIS and mNIS cannot be explained by their different $K_{\mathrm{m}}$ values for sodium.

\section{Expression levels of $h$ NIS and $m$ NIS}

To determine whether the difference in iodide uptake activity between the human and mouse NIS was due to different protein levels in the transiently transfected HEK 293 cells, we performed immunoblot analyses. In the first set of experiments (Fig. 2A), we used a purified rabbit polyclonal antibody, known as antibody 25 anti-mNIS, directed against the mNIS C-terminus. Lane 1 shows a typical profile obtained with extracts from mNIS-expressing HEK 293 cells. Generally, protein species migrating as four broad bands were obtained. The protein fraction migrating at a molecular weight of $\sim 90 \mathrm{kDa}$ corresponds to the monomeric form of the fully glycosylated protein (Levy et al. 1997). Immunoreactivity was also found with a $55 \mathrm{kDa}$ protein; this molecular weight is compatible with a partially glycosylated NIS form (Levy et al. 1997). Generally, the antibody also reacted with two other polypeptides migrating as broad bands at 130 and $180 \mathrm{kDa}$. These fractions presumably correspond to the NIS dimer and/or its multimeric form. The ratios of these bands to the $90 \mathrm{kDa}$ band were very similar over all the conditions tested. Despite the high concentrations of reducing agent $(0.1 \mathrm{M} \mathrm{DTT})$ and the presence of detergent, only a fraction of the total protein expressed in HEK 293 cells was detected in a monomeric form. Interestingly, the same anti-mouse NIS antibody 25 immunoreacted with the human NIS (Fig. 2A, lane 2), probably recognizing the four terminal

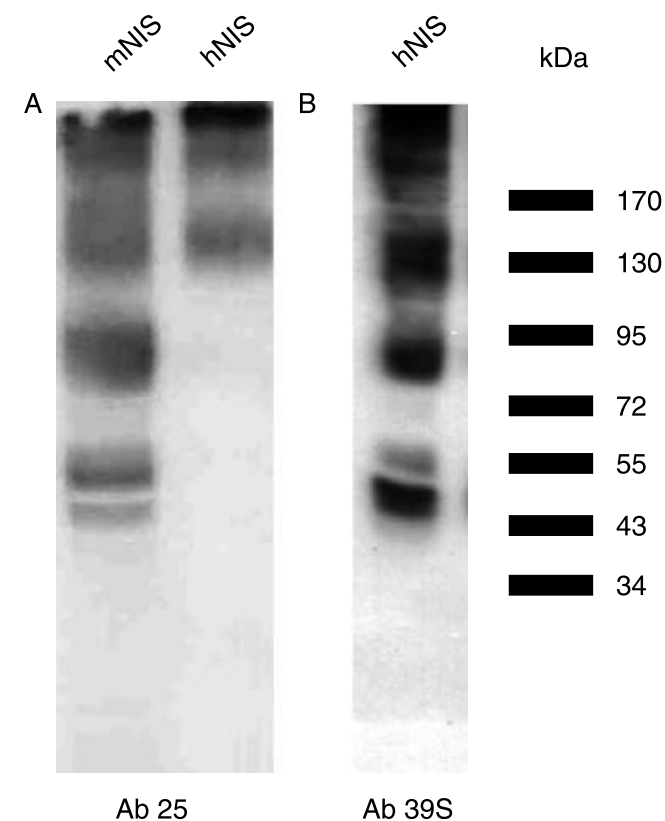

Figure 2 Western blot of hNIS and $\mathrm{mNIS}$ total protein extracts using two different anti-NIS C-terminal-specific antibodies. Equal amounts $(10 \mu \mathrm{g})$ of total protein extracts were separated on SDS-10\% PAGE in the presence of $100 \mathrm{mM}$ DTT and analyzed by immunoblotting. (A) NIS proteins were revealed with the purified rabbit polyclonal antibody 25 anti-mNIS that is directed against the mNIS C-terminal extremity. (B) NIS proteins were revealed with the mouse monoclonal antibody 395 anti-hNIS. The Ab 39S anti-hNIS immunoreacts with a portion of the cytoplasmic C-terminal domain comprising amino acids 580-600. The immunoblot shown is representative of four independent experiments. Molecular weight markers (in $\mathrm{kDa}$ ) are indicated.

amino acids that are identical in the two sequences. Surprisingly, however, the antibody did not detect any proteins migrating at molecular weights corresponding to the monomeric forms of hNIS. To confirm that monomeric hNIS was indeed present in these samples, we stained blots with the mouse monoclonal anti-hNIS antibody 39S. Ab 39S anti-NIS recognizes a portion of the cytoplasmic C-terminal domain (comprising amino acids 580-600). Immunoblotting with this antibody revealed a commonly observed pattern that corresponds to the migration of the different NIS protein species, including the monomeric forms (Fig. 2B). Therefore, the affinity-purified anti-mouse antibody 25 fraction recognizes the human NIS but only immunoreacts with the dimeric and multimeric forms of the protein. Consequently, this antibody could not be used to determine and compare the total protein expression levels in the hNIS- and mNISexpressing cells, and thus to address whether different protein levels could account for the different iodide uptake levels seen between the two orthologs. To overcome this issue, we engineered DNA constructs coding for proteins with their C-termini fused to six successive histidine residues (His-tag), allowing the assessment of protein expression levels using a commercially available anti-His-tag-specific antibody. 
Incorporation of a C-terminal histidine tag does not alter the kinetic properties of $h$ NIS or $m$ NIS

The C-terminal $\mathrm{His}_{6}$-tagged proteins were referred to as hNISH and mNISH. When compared with their non-tagged wild-type counterparts, they displayed no significant differences in the iodide uptake levels. The results shown (Table 1) are an average of three independent experiments, each performed in triplicate. Similar to hNIS, hNISH accumulates iodide $39 \%$ as efficiently as mNIS (set at $100 \%)$. mNISH showed a slightly lower (85\%) iodide uptake level compared with mNIS.

We next determined the $K_{\mathrm{mI}}$ values for the tagged proteins and obtained $8 \cdot 4 \pm 1 \mu \mathrm{M}$ for hNISH and $24 \cdot 6 \pm 1 \cdot 9 \mu \mathrm{M}$ for $\mathrm{mNISH}$ (Table 1). These values are not significantly different from those found for the non-tagged proteins. We also measured $V_{\text {max }}$ values for hNISH and $\mathrm{mNISH}$, obtaining values corresponding to $24 \cdot 5$ and $83 \cdot 7 \%$ of the mNIS value respectively (Table 1). Subsequently, we analyzed the kinetic properties of the $\mathrm{Na}^{+}$-dependent iodide uptake $\left(K_{\mathrm{mNa}}\right)$ in the hNISH- and mNISH-expressing HEK 293 cells. The $K_{\mathrm{m}}$ values of $\mathrm{Na}$ for hNISH and mNISH were $92.6 \pm 12.8 \mathrm{mM}$ and $59.6 \pm 8.3 \mathrm{mM}$ respectively. Again, no differences between the histidine-tagged and wild-type proteins (Table 1) were observed.

\section{$h$ NISH- and $m$ NISH-expressing cells show similar total NIS protein levels}

To assess the protein expression levels of the two His-tagged orthologs in HEK 293 cells, we performed immunoblotting experiments with the histidine-tagged proteins and the anti$\mathrm{His}_{4}$ antibody. In the transiently transfected cells, the level of total $\mathrm{mNISH}$ protein was only about $10 \%$ higher than that of hNISH (Fig. 3A and C). This small difference in the protein levels cannot account for the important difference in the transport activity observed between the two proteins.

The $m$ NISH protein is efficiently targeted to the plasma membrane

NIS targeting to the plasma membrane was studied by surface biotinylation experiments using His-tagged NIS-expressing HEK 293 cells. The entire biotinylated protein fraction was isolated with streptavidin beads and was immunoblotted using the anti-His-tag antibody (Fig. $3 \mathrm{~B}$ and C). Our results showed that despite the similar protein expression levels of $\mathrm{mNISH}$ and hNISH, the relative quantity of the mouse protein at the plasma membrane was $2 \cdot 5$-fold higher than that of the human protein.

\section{Subcellular localization of $h$ NIS and mNIS proteins}

The intracellular localization of the hNIS and mNIS proteins was studied by immunocytochemistry with the anti-mNIS $\mathrm{Ab} 25$ and anti-hNIS $\mathrm{Ab} 39 \mathrm{~S}$ antibodies.

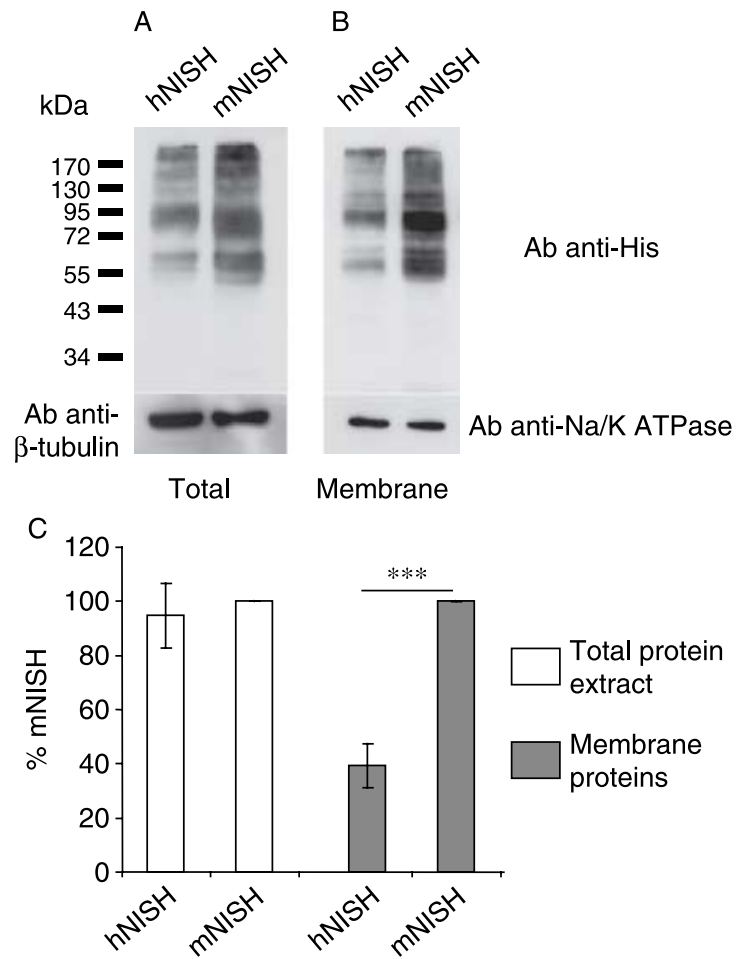

Figure 3 NIS protein expression levels in $\mathrm{hNISH}$ - and $\mathrm{mNISH}$ transfected HEK 293 cells. (A and B) Two days after transfection, cells were incubated with a membrane-impermeant biotinylation reagent and processed as described in the Materials and Methods section. Equal amounts of total protein extracts (A) and biotinylated protein extracts (B) were separated by SDS-10\% PAGE. The C-terminally histidine-tagged mouse and human NIS proteins were analyzed by immunoblotting using an anti-His ${ }_{4}$-specific antibody. PVDF membranes were stripped and reprobed with anti-tubulin (total protein) or anti- $\mathrm{Na} / \mathrm{K}$ ATPase (biotinylated proteins) antibodies. The immunoblot shown is representative of four independent experiments. Molecular weight markers (in kDa) are indicated. (C) Quantification of total and biotinylated proteins. Scanned images of autoradiographic films were analyzed using ImageQuant (Amersham) software. Values are expressed as percentages of $\mathrm{mNISH}$ levels (set at $100 \%$ ) and are means of four independent experiments. ${ }^{* * *} P<0 \cdot 0001$.

We performed a statistical analysis, counting over 6000 cells for each experimental condition with an average transfection yield of $70 \%$. Whereas the mNIS protein was clearly localized at the plasma membrane in $90 \%$ of the transfected cells (Fig. 4), the hNIS protein distribution was more heterogeneous. We noticed great variability in the subcellular localization of the hNIS protein (see quantification of the NIS-stained cells in Fig. 4B). Although $79 \cdot 3 \pm 17 \cdot 2 \%$ of the transfected cells showed hNIS-specific immunostaining at the plasma membrane, in $40 \cdot 1 \pm 16 \cdot 9 \%$ of the cells, hNIS-specific labeling was predominantly intracellular. In the latter cells, extensive immunofluorescence typically appeared as broad patches dispersing throughout the cytoplasm. The mNIS-specific staining generally extended into numerous plasma 
A
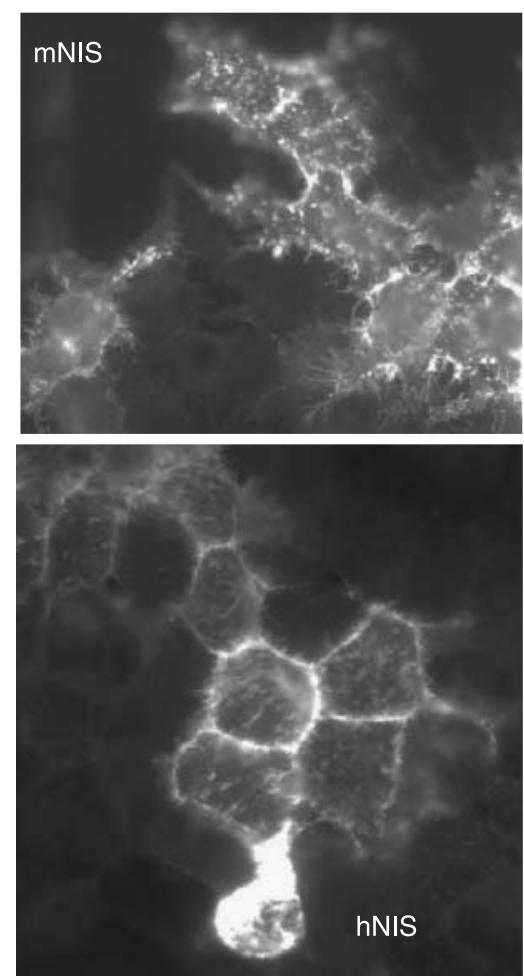
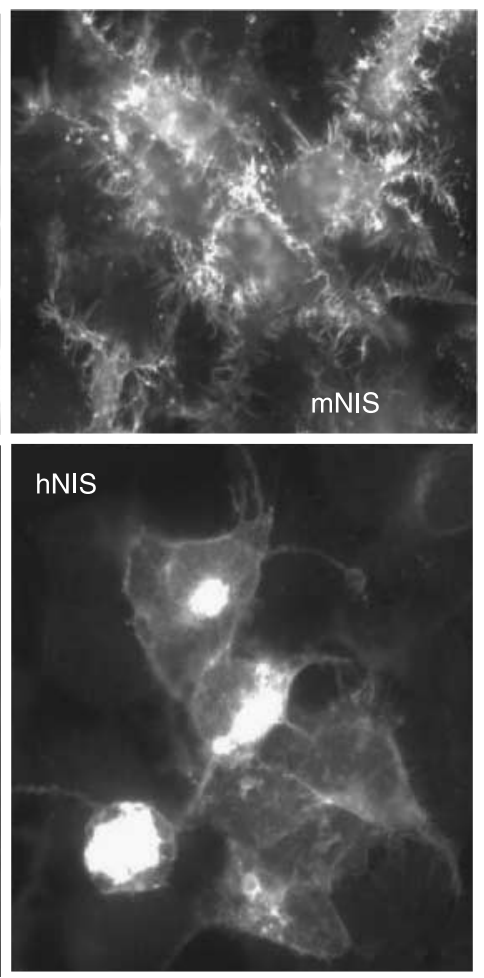

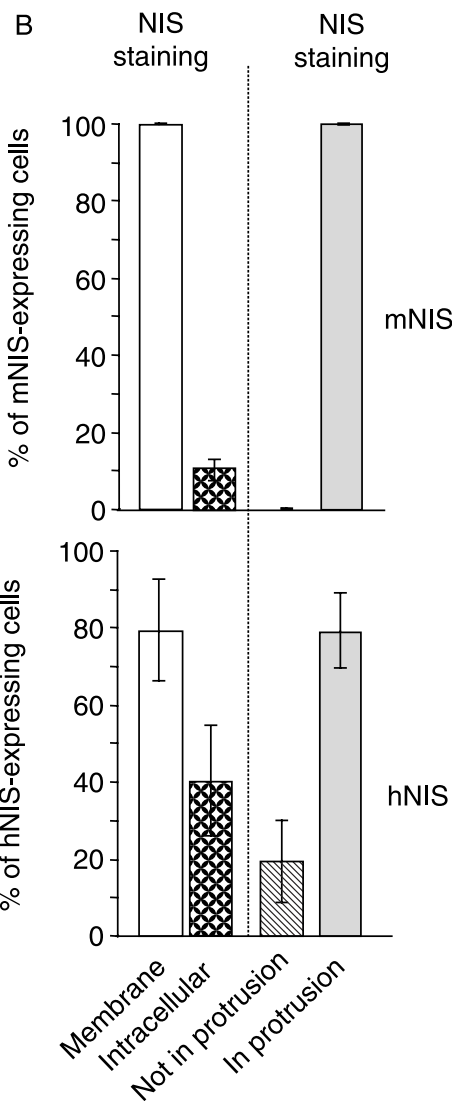

Figure 4 Immunolocalization of hNIS and mNIS in transiently transfected HEK 293 cells. (A) Staining was performed 2 days after transfection with the polyclonal anti-mNIS antibody 25 (upper panels) and the monoclonal anti-hNIS antibody 395 (lower panels). Images shown are representative of four independent experiments. (B) Statistical analysis of mouse and human subcellular NIS localization. Values are representative of six independent experiments, and for each experiment 50 different images were acquired.

membrane protrusions, which was not observed with hNIS. Similar experiments were performed with hNISHand mNISH-expressing cells, and in both cases the number of cells showing intracellular localization of NIS was about $20 \%$ (Table $2 ; 23 \cdot 4 \pm 6 \cdot 4 \%$ for hNISH and $19 \cdot 7 \pm 4 \cdot 6 \%$ for $\mathrm{mNISH})$. Thus, the introduction of a C-terminal histidine tag modulated the subcellular localization of both proteins and abolished the differences

Table 2 Statistical analysis of subcellular natrium iodide symporter (NIS) localization in transfected human embryonic kidney (HEK) 293 cells, and the form of the NIS-specific immunostaining. Values are expressed as a percentage of the total number of NIS-stained cells

\begin{tabular}{|c|c|c|c|c|}
\hline & $\begin{array}{l}\text { Cells with membrane NIS } \\
\text { staining }(\%)\end{array}$ & $\begin{array}{l}\text { Cells with intracellular } \\
\text { NIS staining }(\%)\end{array}$ & $\begin{array}{l}\text { Cells without NIS staining } \\
\text { in protrusions }(\%)\end{array}$ & $\begin{array}{l}\text { Cells with NIS staining in } \\
\text { protrusions }(\%)\end{array}$ \\
\hline hNIS & $79 \cdot 3 \pm 17 \cdot 2$ & $40 \cdot 1 \pm 16 \cdot 9$ & $19 \cdot 7 \pm 10 \cdot 5$ & $80 \cdot 3 \pm 12 \cdot 6$ \\
\hline hNISH & $99 \cdot 0 \pm 1 \cdot 4$ & $23 \cdot 4 \pm 6 \cdot 4$ & $8 \cdot 3 \pm 1 \cdot 9$ & $91 \cdot 7 \pm 3 \cdot 5$ \\
\hline $\mathrm{mNISH}$ & $98 \cdot 4 \pm 3 \cdot 3$ & $19 \cdot 7 \pm 4 \cdot 6$ & $5 \cdot 3 \pm 2 \cdot 3$ & $94 \cdot 7 \pm 3 \cdot 9$ \\
\hline hNISmCter & $99 \cdot 9 \pm 0 \cdot 1$ & $27 \cdot 8 \pm 1 \cdot 7$ & $17 \cdot 4 \pm 2 \cdot 4$ & $82 \cdot 6 \pm 1 \cdot 7$ \\
\hline mNIShCterH & $100 \cdot 0 \pm 0 \cdot 0$ & $32 \cdot 5 \pm 5 \cdot 9$ & $19 \cdot 2 \pm 6 \cdot 8$ & $80 \cdot 8 \pm 5 \cdot 9$ \\
\hline h4m9 & $100 \cdot 0 \pm 0 \cdot 0$ & $10 \cdot 8 \pm 3 \cdot 4$ & $4 \cdot 4 \pm 2 \cdot 4$ & $95 \cdot 6 \pm 2 \cdot 5$ \\
\hline m4h9 & $100 \cdot 0 \pm 0 \cdot 0$ & $17 \cdot 9 \pm 4 \cdot 4$ & $13 \cdot 4 \pm 4 \cdot 8$ & $86 \cdot 6 \pm 4 \cdot 8$ \\
\hline h8m5 & $99 \cdot 9 \pm 0 \cdot 1$ & $18 \cdot 5 \pm 2 \cdot 9$ & $10 \cdot 2 \pm 3 \cdot 2$ & $89 \cdot 8 \pm 3 \cdot 9$ \\
\hline m8h5 & $100 \cdot 0 \pm 6 \cdot 6$ & $22 \cdot 3 \pm 2 \cdot 7$ & $15 \cdot 4 \pm 2 \cdot 6$ & $84 \cdot 6 \pm 7 \cdot 2$ \\
\hline
\end{tabular}


previously seen between the two wild-type proteins. The C-terminal modification of hNIS decreased the number of cells showing intracellular localization of the protein by $50 \%$ (Table 2) when compared with the wild-type protein. An inverse effect was observed with the mouse protein, where the histidine tag led to a twofold increase in the number of cells showing intracellular localization.

\section{Generation of mouse/human chimeras}

To identify the protein regions potentially responsible for the differences in the iodide uptake activity and subcellular localization between hNIS and mNIS, we replaced several regions of the mouse protein with corresponding portions from the human protein and vice versa (Fig. 5). Three transmembrane domains (similar in size) and the C-terminal extremity of the orthologs were exchanged. These constructs were named according to the sequential order (starting at the N-terminus) of the individual components. Thus, hNISmCter denotes a chimera that is composed of the majority of the human NIS protein, but containing the mouse cytoplasmic C-terminus. Its reciprocal chimeric construct is

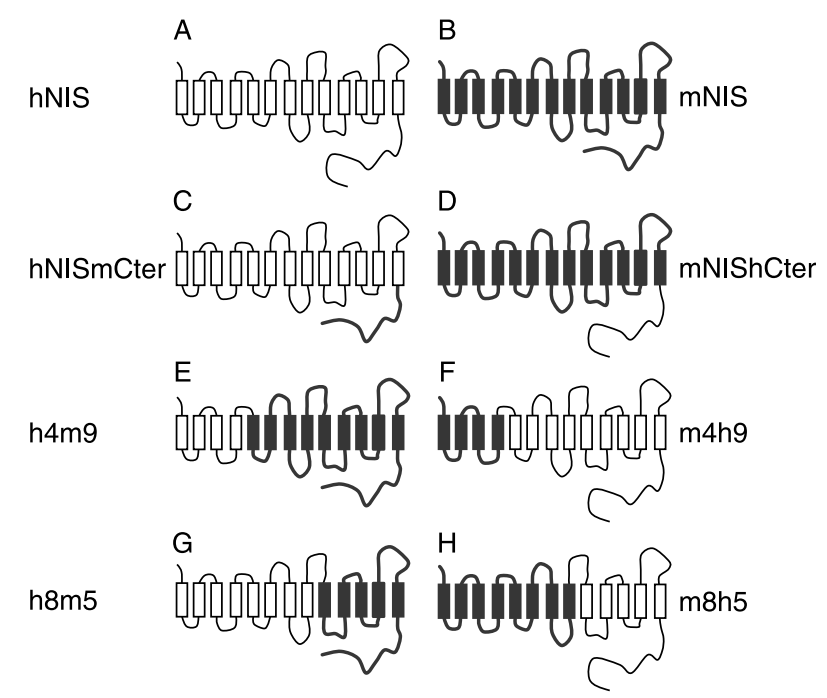

Figure 5 Structural model of human and mouse NIS and chimeras. Topology model deduced from previous data (Levy et al. 1998b) of (A) wild-type human NIS protein (hNIS); (B) wild-type mouse NIS protein (mNIS); (C) human NIS protein with a mouse C-terminus (hNISmCter); (D) mouse NIS protein with a human C-terminus (mNIShCter); (E) NIS chimeric protein composed of four N-terminal human transmembrane segments and nine C-terminal mouse transmembrane segments (h4m9); (F) NIS chimeric protein composed of four N-terminal mouse transmembrane segments and nine C-terminal human transmembrane segments (m4h9); (G) NIS chimeric protein composed of eight $\mathrm{N}$-terminal human transmembrane segments and five C-terminal mouse transmembrane segments (h8m5); (H) NIS chimeric protein composed of eight $\mathrm{N}$-terminal mouse transmembrane segments and five C-terminal human transmembrane segments (m8h5). Segments corresponding to the mouse protein are in bold.
mNIShCter, in which the cytoplasmic C-terminus of the mouse protein is replaced by the corresponding portion of the human NIS. We engineered four other chimeras, namely $\mathrm{h} 4 \mathrm{~m} 9, \mathrm{~m} 4 \mathrm{~h} 9$, h8m5, and $\mathrm{m} 8 \mathrm{~h} 5$. h4 $4 \mathrm{~m} 9$ contains the $\mathrm{N}$-terminus and the first four transmembrane-spanning segments from the human protein, fused to the final nine transmembrane segments and the C-terminal region of the mouse protein. Inversely, chimera $\mathrm{m} 4 \mathrm{~h} 9$ is composed of the four N-terminal mouse transmembrane-spanning segments and the nine subsequent human transmembrane segments, and so forth.

The cytoplasmic C-terminus is not responsible for the differences in the kinetic properties between the hNIS and mNIS proteins

Iodide uptake measurements taken at $30 \mathrm{~min}$ for hNISmCter and mNIShCter revealed no significant differences from their corresponding wild-type counterparts, i.e., hNIS and mNIS respectively (Fig. 6; Table 1). Furthermore, hNISmCter and hNIS showed similar $K_{\mathrm{m}}$ values for iodide, as did mNIShCter and mNIS (Fig. 7; Table 1). At the same time, the $K_{\mathrm{m}}$ for sodium of mNIShCter was more similar to hNIS than to mNIS (Fig. 7), suggesting that the C-terminus of the protein can modify the sodium recognition site of the transporter. Despite this relatively small effect, our overall results indicate that the NIS C-terminus is not involved in the transport activity of the protein.
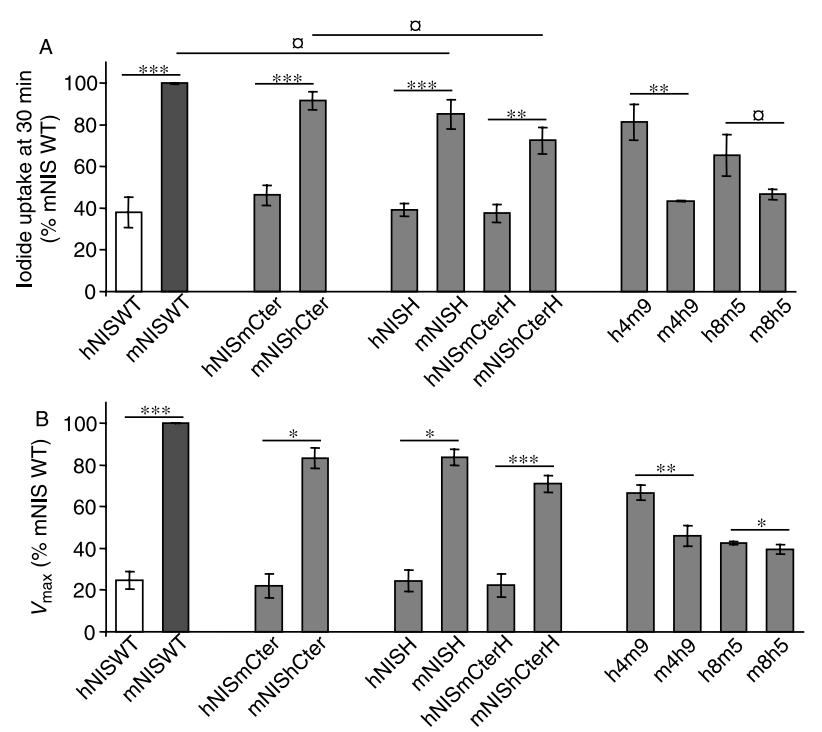

Figure 6 Kinetic properties of wild-type and chimeric NIS proteins. (A) lodide uptake with transfected HEK 293 cells after 30 min of incubation with $30 \mu \mathrm{M} \mathrm{Nal}^{-}$. (B) Calculated $V_{\max }$ values. All values are expressed as percentages of wild-type $\mathrm{mNIS}$ (set at $100 \%$ ) and are means of at least three experiments. ${ }^{* * *} 0 \cdot 0001<P<0 \cdot 0005$. ${ }^{* *} 0 \cdot 001<P<0 \cdot 002$. ${ }^{*} P<0 \cdot 01$. ${ }^{a} 0 \cdot 01<P<0 \cdot 05$. 


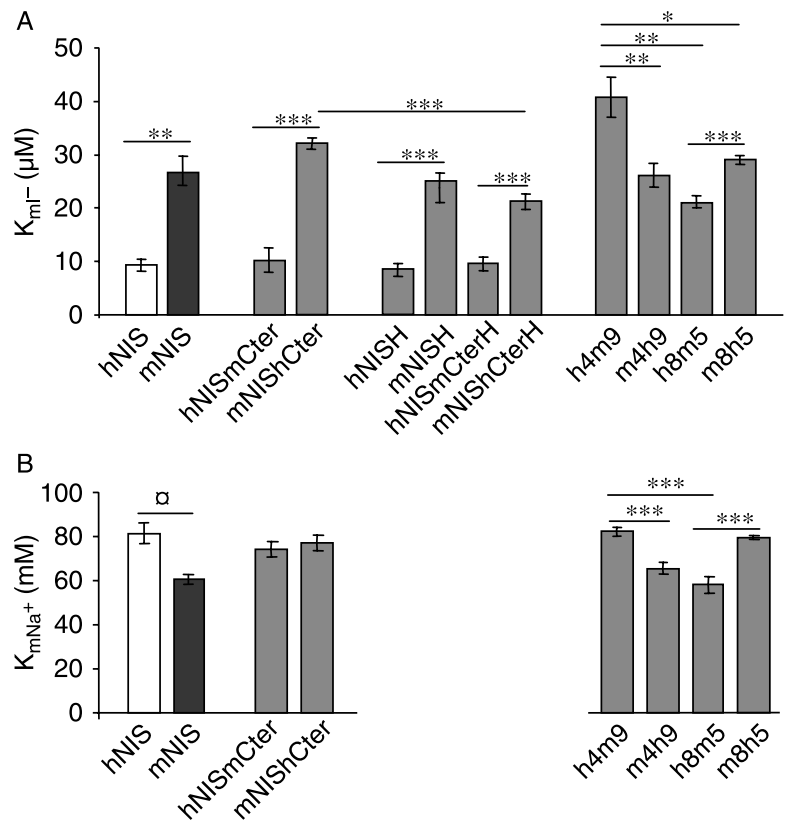

Figure 7 Transport properties of wild-type and chimeric NIS proteins expressed in transfected HEK 293 cells. (A) Calculated values for the iodide transport constants $\left(K_{\mathrm{ml}}\right)$. (B) Calculated values for the sodium transport constants $\left(K_{\mathrm{mNa}}\right)$. Values are means of at least three experiments. ${ }^{* * *} 0 \cdot 0001<P<0 \cdot 0005$. ${ }^{* *} 0 \cdot 001<P<0 \cdot 002$. $* P<0 \cdot 01$. $0 \cdot 1<P<0 \cdot 035$.

\section{Immunocytochemistry with the cytoplasmic C-terminal chimeras}

With the aim of immunolocalizing both the hNISmCter and mNIShCter chimeras in the transfected HEK cells using a single antibody, we fused a histidine tag to the C-terminal extremities of both proteins. The resulting constructs were named hNISmCterH and mNIShCterH. The results of the immunofluorescence experiments were similar to those obtained from the His-tagged wild-type proteins, i.e., hNISH and mNISH (Fig. 8): no significant differences between the subcellular localization of hNISmCterH and that of mNIShCterH were detected. When compared with the tagged wild-type proteins, the percentage of cells showing intracellular immunoreactivity increased by $\sim 10 \%$ for both chimeric proteins. The percentage of cells showing no NISspecific staining in the plasma membrane protrusions was also increased. Taken together, these observations indicate that the final residues of the C-terminal extremity play a role in determining the cellular distribution of the NIS protein.

Analysis of the kinetic properties of NIS chimeras $h 4 m 9, m 4 h 9$, $h 8 m 5$, and $m 8 h 5$ suggests that amino acids within transmembrane domains (TM) 5-13 are involved in the different kinetic behaviors of hNIS and $m$ NIS

As with the wild-type human and mouse NIS, the iodide uptake capacities and the $V_{\max }$ values of the four chimeras were determined in the transfected HEK 293 cells (Fig. 6;

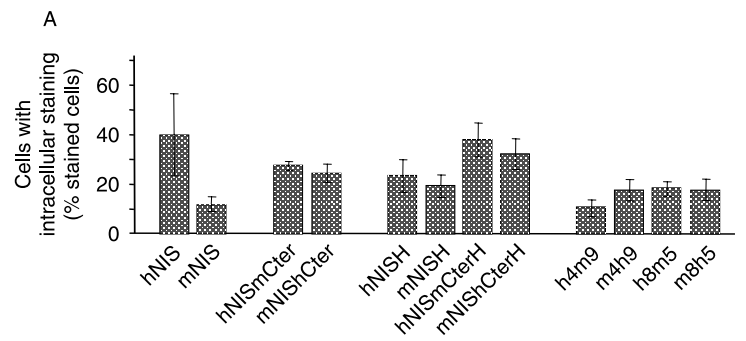

B

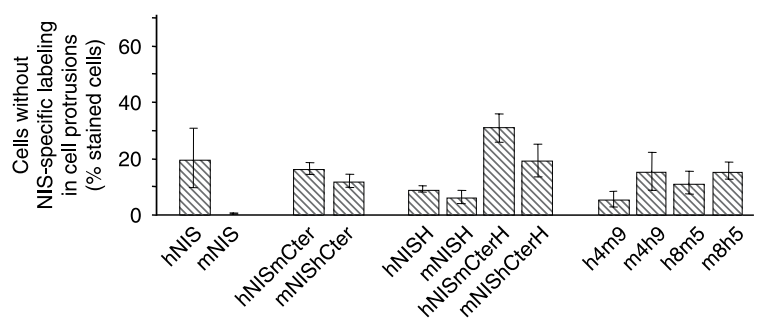

Figure 8 Statistical analysis of the subcellular NIS localization and cell morphology of HEK 293 cells transiently transfected with wildtype NIS or chimeras. (A) Percentage of NIS-specific stained cells showing intracellular localization of the NIS-specific labeling. (B) Percentage of NIS-stained cells without labeling in cell protrusions. Values are representative of six independent experiments, and for each assay 50 different images showing $\sim 40$ cells each were acquired.

Table 1). Surprisingly, the uptake activities of all four chimeric proteins were higher than those obtained with the wild-type human NIS, although only chimera $\mathrm{h} 4 \mathrm{~m} 9$ attained values similar to those found with the wild-type mouse NIS. The relative uptake activity of the chimera-expressing and wildtype NIS-expressing cells was, in descending order, mNIS $>$ $\mathrm{h} 4 \mathrm{~m} 9>\mathrm{h} 8 \mathrm{~m} 5>\mathrm{m} 4 \mathrm{~h} 9=\mathrm{m} 8 \mathrm{~h} 5>\mathrm{hNIS}$. These results suggest that the region between TM5 and TM13 and particularly the portion between TM9 and TM13 are responsible for the higher uptake activity of the mouse NIS. The $V_{\max }$ values obtained with h8m5-, m8h5-, h4m9- and m4h9-expressing cells were all higher than those obtained with hNISexpressing cells. The calculated $V_{\max }$ values of the chimeraexpressing cells showed the following succession in decreasing order: $\mathrm{mNIS}>\mathrm{h} 4 \mathrm{~m} 9>\mathrm{h} 8 \mathrm{~m} 5=\mathrm{m} 4 \mathrm{~h} 9=\mathrm{m} 8 \mathrm{~h} 5>\mathrm{hNIS}$. In contrast to the uptake activity, the $V_{\max }$ value obtained in h8m5-expressing cells was similar to that of $\mathrm{m} 4 \mathrm{~h} 9$ - and m8h5-expressing cells. The reason for this discrepancy is unclear, and possibly involves a modification of the sodiumiodide coupling efficiency of the $\mathrm{h} 8 \mathrm{~m} 5$ chimera.

From these results, it appears that sequence differences between hNIS and mNIS in the region from TM5 to TM13 underlie the observed disparities in protein expression and uptake activity between the two orthologs. Unfortunately, we cannot draw any further conclusions concerning the relative importance of the various sections extending from TM5 to TM8 and from TM9 to TM13. 
The iodide recognition site is located between TM1 and TM8

We determined the kinetic constants for the iodide transport catalyzed by all the chimeric, histidine-tagged, and the wildtype mouse and human NIS proteins (Fig. 7A). Among the $K_{\mathrm{mI}}$ values of chimeras $\mathrm{h} 4 \mathrm{~m} 9, \mathrm{~m} 4 \mathrm{~h} 9, \mathrm{~m} 8 \mathrm{~h} 5$, and $\mathrm{h} 8 \mathrm{~m} 5$, the latter showed the smallest value $(20 \cdot 7 \pm 0 \cdot 7 \mu \mathrm{M})$; this value was even smaller than that obtained with the wild-type mNIS. This observation suggests that the domain extending from TM1 to TM8 is involved in the recognition of the iodide ion. However, since the $K_{\mathrm{mI}}$ for $\mathrm{h} 8 \mathrm{~m} 5$ is similar to that of the Histagged $\mathrm{mNIShCterH}$, the above proposed suggestion must be questioned. We observed the highest $K_{\mathrm{mI}}$ in $\mathrm{h} 4 \mathrm{~m}$ 9-expressing cells, implying that an interaction between amino acids within TM1-TM4 and amino acids within TM5-TM13 is modified in the $\mathrm{h} 4 \mathrm{~m} 9$ chimera. Taken together, we conclude that the iodide recognition site is located between TM1 and TM8.

The cytoplasmic C-terminal portion appears to interact with or be close to the sodium recognition site

We measured the effect of increasing sodium concentrations (ranging from 2.5 to $160 \mathrm{mM}$ ) on the rates of iodide transport at $4 \mathrm{~min}$. We found higher $K_{\mathrm{m}}$ values for $\mathrm{Na}$ with hNIS than with mNIS (see above); introducing a histidine tag at the C-terminal extremity of the wild-type proteins did not modify these values. Surprisingly, replacing the cytoplasmic C-terminal portion of mNIS with the corresponding portion of hNIS (see mNIShCter) altered the constant for the sodium-dependent activation of iodide transport, resulting in a value similar to the $K_{\mathrm{mNa}}$ obtained with hNIS. This finding suggests that the cytoplasmic C-terminal extremity and the protein domain involved in sodium recognition either interact or are at least in close proximity.

When studying the chimeric proteins, we observed that the $K_{\mathrm{mNa}}$ values for the $\mathrm{h} 4 \mathrm{~m} 9$ and $\mathrm{m} 8 \mathrm{~h} 5$ transporters were similar to that of hNIS (approx. $80 \mathrm{mM} \mathrm{Na}$ ). However, the $K_{\mathrm{mNa}}$ for the $\mathrm{m} 4 \mathrm{~h} 9$ and $\mathrm{h} 8 \mathrm{~m} 5$ proteins were similar to that of $\mathrm{mNIS}$ $(60 \mathrm{mM} \mathrm{Na})$. Thus, the presence of either section TM1TM4 or section TM9-TM13 of the mouse protein lowers the $K_{\mathrm{mNa}}$. Additional analysis is now required to confirm this observation and to elucidate this effect at a molecular level.

\section{Discussion}

Previous work has shown that the rat NIS allows superior iodide accumulation when compared with the human NIS (Heltemes et al. 2003, Zhang et al. 2005). In this study, we used ${ }^{125} \mathrm{I}$ uptake experiments and measurements of the iodide and sodium transport constants to compare the mouse and human NIS that had been transiently expressed in HEK 293 cells. We also performed immunocytolocalization studies and western blot analysis to characterize total and cell surfacelocalized proteins. These studies revealed several significant differences between the two proteins. In order to better understand these differences at a molecular level, we engineered, expressed, and analyzed histidine-tagged and chimeric forms of the two orthologs.

In this study, we used the mouse NIS identified by Perron et al. (2001). Its sequence and known functional properties are similar to those of its rat counterpart (data not shown). Our results concerning the kinetic properties of hNIS and mNIS revealed several significant differences between the human and mouse orthologs with respect to their iodide and sodium transport properties.

Heltemes et al. (2003) compared 11 cell lines expressing either rNIS or hNIS and found that the uptake activity was always lower in the hNIS-expressing cells. We also observed that the uptake activity in hNIS-expressing cells was lower than that in mNIS-expressing cells, using several cell lines (HEK 293, COS-7, C6, HT29, etc.; data not shown). We chose HEK 293 cells for their high transfection efficiency and higher iodide uptake activity. Using COS-7 cells, we also obtained high transfection efficiencies, but the NIS proteins were not predominantly localized to the plasma membrane as they were in HEK 293 cells. It was therefore more difficult to analyze modifications of protein localization in COS-7 cells. However, all the most significant effects described in this study were also observed with COS-7 cells.

We observed that the transport constant for iodide transfer is $2 \cdot 5$-fold lower with the human NIS than that with the mouse NIS when expressed in HEK 293 cells $\left(K_{\mathrm{mI}}\right.$ values: $9 \pm 0 \cdot 8 \mu \mathrm{M}$ for hNIS and $26 \cdot 4 \pm 3 \cdot 5 \mu \mathrm{M}$ for mNIS). These results were confirmed in an oocyte expression system (data not shown). The obtained values are identical to those obtained by the group of Dr N Carrasco for the human (De la Vieja et al. 2005) and rat NIS (Dohan et al. 2002) expressed in the COS-7 cell line. However, our values differ from those obtained by Zhang et al. (2005), who obtained $K_{\mathrm{mI}}$ values for hNIS and rNIS (also expressed in COS-7 cells) of 132 and $122 \mu \mathrm{M}$ respectively. The reasons for these discrepancies are unknown. We also determined the transport constant of sodium transfer. Our data only identified a small difference between the constants for the human and mouse NIS proteins ( $K_{\mathrm{mNa}}$ values: $82 \pm 8.1 \mathrm{mM}$ for hNIS and $59 \pm 4 \mathrm{mM}$ for mNIS). Again, our results obtained with mNIS are similar to the $K_{\mathrm{mNa}}$ values obtained for rNIS ( $45 \mathrm{mM}$ ) by Dr Carrasco's group (Dohan et al. 2002), but differ markedly from those reported by Zhang et al. (2005). The latter group obtained a $K_{\mathrm{mNa}}$ value for rNIS of $22 \mathrm{mM}$; the constant for hNIS was not given. We therefore strongly suspect that the recognition site for iodide shows more important differences between the NIS orthologs than the recognition site for sodium does.

Significant differences were also found between the $V_{\max }$ values of the two proteins. The $V_{\max }$ obtained for mNIS was four times that of hNIS. The same result was obtained by S M Jhiang's group with the rat NIS. Using cell surface proteinlabeling experiments, we found that the plasma membrane localization of the mouse protein was only $2 \cdot 5$-fold higher than that of the human protein, and therefore cannot alone account for the observed differences in the $V_{\max }$ values of the 
two proteins. We therefore concluded that the different $V_{\max }$ values likely reflected a higher turnover rate in the mouse protein. By contrast, Zhang et al. (2005) found a direct relationship between the higher $V_{\max }$ values obtained for the rat protein over its human counterpart and the increased protein levels at the plasma membrane. Further experiments are required to clearly establish the turnover numbers for iodide transport for the human and mouse NIS proteins to elucidate this discrepancy. A modification in the conformation equilibrium required for the transport activity could account for the observed difference in the NIS turnover numbers for the two orthologs. As mentioned above, the $K_{\mathrm{mI}}$ value of the human transporter is considerably lower than that of the mouse transporter. This lower value suggests that the iodide-binding site and/or the iodide occluding states are different between the two orthologs. A modification in the conformation equilibrium could then lead to a concomitant change in the $K_{\mathrm{m}}$ and $V_{\max }$ values. A similar phenomenon has been observed in site-directed mutagenesis experiments on the serotonin transporter (hSERT) and the dopamine transporter (Loland et al. 2002). Kristensen et al. (2004) reported that two single mutations in the hSERT sequence increased the $K_{\mathrm{m}}$ values that, in turn, led to an increase in the corresponding $V_{\max }$ values. Loland and collaborators described a mutation in the dopamine transporter that increased the apparent substrate affinity (lower value) and, consequently, led to a decrease in the $V_{\max }$.

Analyzing the transport properties of chimeric proteins prepared from orthologs has been successfully used to identify functional domains within the serotonin transporter (Barker et al. 1994, Mortensen et al. 2001) and the sodium/glucose symporter (Nagata \& Hata 2006). Unfortunately, to date, studies with the chimeric NIS orthologs have not allowed the identification of the specific amino acids or protein domains involved in iodide recognition or co-substrate translocation. Our analysis of $K_{\mathrm{mI}}$ values, however, suggests that the amino acid residues controlling iodide recognition and/or the conformation of this site are located in the region extending from the $\mathrm{N}$-terminus to the transmembrane domain 8 . Zhang et al. (2005) also concluded that the differences in the transport activity and plasma membrane localization of the two orthologs are due to sequence differences in the region extending from the $\mathrm{N}$-terminus to transmembrane domain 7. However, we also observed that all the chimeras showed higher $K_{\mathrm{mI}}$ and $V_{\max }$ values than did hNIS, and lower $K_{\mathrm{mI}}$ and $V_{\max }$ values than did mNIS.

With secondary transporters, studies of the structurefunction relationship by a chimeric approach have only been used successfully with few proteins (see examples above). This may be due to the few known X-ray structures of secondary transporters, such as the sodium-driven aspartate/glutamate transporter from Pyrococcus horikoshii (Yernool et al. 2004, Boudker et al. 2007) and the proton-driven lactose permease from Escherichia coli (Abramson et al. 2003). Interestingly, in both proteins, the amino acids that contribute to the binding of the co-substrate are localized in several remote transmembrane regions with regard to the protein's primary structure. In the folded proteins, however, these regions form appropriate environments for substrate binding.

In our western blot experiments, hNIS- and mNISspecific antibodies revealed that the proteins generally migrate in SDS-PAGE as polypeptides with four different apparent molecular weights. On the immunoblots, we detected two bands with molecular weights compatible with either partially $(55 \mathrm{kDa})$ or fully glycosylated $(90 \mathrm{kDa})$ monomeric protein, as well as two additional broad bands (130-170 kDa) formed by the dimeric and/or multimeric forms of glycosylated proteins (Levy et al. 1997). Despite the use of increasing concentrations of reducing agent (up to $100 \mathrm{mM} \mathrm{DTT}$ ), the dimeric and multimeric NIS species were present in all experiments, suggesting that the NIS dimers and multimers are stabilized by very strong interactions.

Surprisingly, on the immunoblots with membranes from the transfected HEK 293 cells, our affinity-purified antimouse NIS Ab 25 antibody fraction recognized both the mouse and human NIS proteins. The same antibody also gave hNIS-specific staining in immunocytochemistry experiments. Unexpectedly, however, this antibody fraction only reacted with the dimeric and multimeric human NIS species, and could therefore not be used for quantification studies of the two proteins. The anti-mouse Ab 25 fraction was produced with a peptide comprising the 16 C-terminal amino acids of the mouse NIS protein. In this portion, only the last four amino acids are identical to the equivalent amino acids in the hNIS sequence. Thus, the affinitypurified $\mathrm{Ab} 25$ anti-mNIS fraction contains an antibody population that specifically recognizes these four amino acids. Even though on our immunoblots the partially or fully glycosylated monomeric NIS proteins were not revealed, their presence in the samples could be detected with our monoclonal anti-human NIS Ab 39S. Thus, the C-terminal extremity of the monomeric human protein is no longer accessible for $\mathrm{Ab} 25$ anti-mNIS binding after SDS-PAGE and immunotransfer onto the PVDF membrane. For quantification experiments, we therefore used an epitope tagging strategy. First, we added an N-terminal Flag sequence that has been successfully used by Levy et al. (1998b) and Zhang et al. (2005) with the rat NIS. However, in our hands, this modification strongly altered the transport activity, precluding its use in our experiments: the iodide uptake activity obtained with the N-terminal Flag-tag construct in the transiently transfected HEK 293 cells was approximately four times lower than that obtained with the wild-type proteins (data not shown). This effect was not observed by Zhang et al. (2005); the reason for this discrepancy is unknown. However, several reports indicate that the fusion of an epitope tag to the amino acid sequence of a transport protein can strongly alter protein function. This was found, for example, with the sodium/glucose symporter (Turner et al. 1996, Bissonnette et al. 1999), another member of the sodium/solute symporter family. 
We next fused a sequence of six histidine residues to the C-terminal extremity of the two NIS proteins. Fortunately, this modification did not induce any major changes in the transport activity of the proteins when expressed in HEK 293 cells (Table 1). The His-tag also left the transport activity and $V_{\max }$ of hNISH intact, while decreases of about $15 \%$ in the iodide uptake activity and $V_{\max }$ were observed for mNISH when compared with mNIS (Table 1). However, the transport constants for iodide and sodium remained unchanged. We observed that fusing the His-tag to the C-terminal extremity of the mouse NIS (mNISH) increased the intracellular retention of the expressed protein in the transfected HEK 293 cells (Table 2; Fig. 8). The four C-terminal amino acids are predicted to be a consensus sequence recognized by PDZ domain-containing proteins. An interaction between the mNIS C-terminus and these proteins may be involved in the proper targeting of NIS to the plasma membrane. Thus, introducing the His-tag adjacent to the potential PDZ recognition site may hamper such interactions and cause the NIS protein to accumulate in the cytoplasmic compartments. It has been shown that interactions with PDZ domain-containing proteins can be an important mechanism for the localization of membrane proteins (Guggino 2004, Weinman et al. 2005).

Opposite results were obtained with the C-terminal Histag fusion construct of the human NIS. Based on the immunofluorescence images of hNISH-transfected cells, we found that fewer cells presented NIS-specific intracellular immunoreactivity than cells transfected with the wild-type human protein. Likewise, the number of cells showing intracellular anti-NIS immunoreactivity when transfected with chimeras $\mathrm{m} 4 \mathrm{~h} 9, \mathrm{~h} 8 \mathrm{~m} 5$, and $\mathrm{m} 8 \mathrm{~h} 5$ was lower than that in hNIS-transfected cells and higher than that in mNIStransfected cells. Only chimera h4m9 showed a localization profile similar to that of mNIS, suggesting that the region between the $\mathrm{N}$-terminus and the TM4 is not involved in determining the subcellular location of the protein. However, this suggestion is far from certain, since chimera m4h9expressing cells showed less NIS-specific intracellular staining than did hNIS-expressing cells. Together, the data obtained with the chimeric proteins suggest that, in addition to the last four amino acids, the region comprising TM5 to the C-terminus could play a role in determining the subcellular distribution of the protein.

We observed that transfected cells displaying strong intracellular hNIS-specific immunostaining often had a round morphology and showed annexin $\mathrm{V}$ labeling (data not shown), indicating the onset of apoptosis. This was not found for mNIS-expressing cells that showed specific immunostaining most often at the plasma membrane and did not show any simultaneous staining of annexin V. It has been reported that the intracellular sodium concentration increases during the early phase of apoptosis (Panayiotidis et al. 2006). This lowers the transmembrane $\mathrm{Na}^{+}$gradient and consequently reduces the driving force for the NIS-mediated sodium-coupled iodide accumulation.
Therefore, in the early-stage apoptotic cells, the NIS protein, although present at the plasma membrane, should not efficiently transport iodide. Thus, a smaller $V_{\max }$ should be found in apoptotic compared with healthy NISexpressing cells. This phenomenon could be partly responsible for the different $V_{\max }$ values found between the hNIS- and mNIS-expressing cells. However, as only $20 \%$ of the hNIS-expressing cells were positive for annexin $\mathrm{V}$, the presence of apoptotic cells in cultures transfected with human NIS cannot alone explain the different $V_{\max }$ values of the two orthologs.

For years, thyroid cancers and their metastases have been efficiently treated with radiotherapy. While NIS-mediated iodide accumulation in malignant thyroid tissue is lower than that in normal thyroid tissue, it is generally sufficient to allow for effective ${ }^{131}$ I-induced cell destruction. NIS expression has also been found in non-thyroidal tumors such as breast cancers, potentially rendering these cells susceptible to radioiodide treatment. Unfortunately, in breast cancer cells, ${ }^{131}$ iodide treatment is impossible because of insufficient NIS function due to incorrect targeting and/or too low NIS levels in the plasma membrane. Therefore, understanding the mechanisms that control the subcellular localization of NIS and characterizing the protein domains that are important for promoting NIS targeting to the plasma membrane will be required to improve the therapeutic use of radioiodide in these tumors.

The study reported here is of particular interest in the recent and highly promising field of NIS-based gene therapy for non-thyroidal cancers (Chung 2002), especially when NIS is used in synergy with other genes such as canstatin (an angiogenic inhibitor; Magnon et al. 2007) or with virotherapy (Dingli et al. 2004, Goel et al. 2007). The targeted transduction and the expression of NIS in cancer cells can allow tumor cell destruction by radioiodine treatment as well as in vivo imaging for the generation and investigation of safe and efficient gene delivery systems. A particular advantage of radiotherapy with ${ }^{131}$ iodide is that internalized isotopes can deliver a local radiation field with cytotoxic doses (across several cell diameters) sufficient to destroy neighboring, possibly untransduced cancer cells (by stander effect). Therefore, important therapeutic effects can be achieved without uniform systemic gene delivery into all tumor cells. However, despite the highly promising results obtained recently (Goel et al. 2007, Magnon et al. 2007), it is still critical to develop better gene delivery systems and to improve the iodide uptake capacity of targeted cells in order to lower the administered radiation doses. As with our experiments, the above-mentioned gene therapy approach is based on the transient expression of NIS in target cells. In view of our observations, the use of mouse NIS would seem to be highly recommended in order to obtain highlevel protein expression during gene therapy. However, in humans, the expression of a mouse-derived protein would probably induce an immune reaction, threatening the success of the radioiodine treatment. A better understanding 
of the molecular mechanisms involved in the posttranscriptional regulation and subcellular distribution of NIS will thus be required to engineer a mainly humanderived NIS protein showing at least the same iodide accumulation capacity as its mouse or rat counterpart.

\section{Acknowledgements}

We greatly appreciate the generous gift of the human NIS plasmid from Prof. S M Jhiang (Ohio State University, Colombus, OH, USA). The authors thank Fanny Graslin for excellent technical assistance. We give our thanks to Dr Xavier Fontana and Eliane Valenti from the Centre Antoine Lacassagne for assisting us with the radioactive iodide experiments. This work was supported by the grants from the ToxNuc \& ToxNucE programs. M D, C B and V N were recipients of fellowships funded by the ToxNuc \& ToxNucE programs. There are no conflicts of interest.

\section{References}

Abramson J, Smirnova I, Kasho V, Verner G, Kaback HR \& Iwata S 2003 Structure and mechanism of the lactose permease of Escherichia coli. Science $301610-615$

Barker EL, Kimmel HL \& Blakely RD 1994 Chimeric human and rat serotonin transporters reveal domains involved in recognition of transporter ligands. Molecular Pharmacology 46 799-807.

Bissonnette P, Noel J, Coady MJ \& Lapointe JY 1999 Functional expression of tagged human $\mathrm{Na}^{+}$-glucose cotransporter in Xenopus laevis oocytes. Journal of Physiology $\mathbf{5 2 0}$ 359-371.

Boudker O, Ryan RM, Yernool D, Shimamoto K \& Gouaux E 2007 Coupling substrate and ion binding to extracellular gate of a sodiumdependent aspartate transporter. Nature 445 387-393.

Chang P, LeGuellec K \& Houliston E 1996 Immunodetection of cytoskeletal structures and the Eg5 motor protein on deep-etch replicas of Xenopus egg cortices isolated during the cortical rotation. Biology of the Cell 88 89-98.

Chung JK 2002 Sodium iodide symporter: its role in nuclear medicine. Journal of Nuclear Medicine 43 1188-1200.

Dai G, Levy O \& Carrasco N 1996 Cloning and characterization of the thyroid iodide transporter. Nature 379 458-460.

De La Vieja A, Ginter CS \& Carrasco N 2004 The Q267E mutation in the sodium/iodide symporter (NIS) causes congenital iodide transport defect (ITD) by decreasing the NIS turnover number. Journal of Cell Science 117 677-687.

De la Vieja A, Ginter CS \& Carrasco N 2005 Molecular analysis of a congenital iodide transport defect: G543E impairs maturation and trafficking of the $\mathrm{Na}^{+} / \mathrm{I}^{-}$symporter (NIS). Molecular Endocrinology 19 2847-2858

Dingli D, Peng KW, Harvey ME, Greipp PR, O'Connor MK, Cattaneo R, Morris JC \& Russell SJ 2004 Image-guided radiovirotherapy for multiple myeloma using a recombinant measles virus expressing the thyroidal sodium iodide symporter. Blood 103 1641-1646.

Dohan O \& Carrasco N 2003 Advances in $\mathrm{Na}(+) / \mathrm{I}(-)$ symporter (NIS) research in the thyroid and beyond. Molecular and Cellular Endocrinology 213 59-70.

Dohan O, Gavrielides MV, Ginter C, Amzel LM \& Carrasco N 2002 $\mathrm{Na}(+) / \mathrm{I}(-)$ symporter activity requires a small and uncharged amino acid residue at position 395. Molecular Endocrinology 16 1893-1902.

Dohan O, De La Vieja A, Paroder V, Riedel C, Artani M, Reed M, Ginter CS \& Carrasco N 2003 The sodium/iodide symporter (NIS): characterization, regulation, and medical significance. Endocrine Reviews 24 48-77.
Goel A, Carlson SK, Classic KL, Greiner S, Power AT, Bell JC \& Russell SJ 2007 Radioiodide imaging and radiovirotherapy of multiple myeloma using VSV(851)-NIS, an attenuated vesicular stomatitis virus encoding the sodium iodide symporter gene. Blood (Epub ahead of print).

Guggino WB 2004 The cystic fibrosis transmembrane regulator forms macromolecular complexes with PDZ domain scaffold proteins. Proceedings of the American Thoracic Society $128-32$.

Heltemes LM, Hagan CR, Mitrofanova EE, Panchal RG, Guo J \& Link CJ 2003 The rat sodium iodide symporter gene permits more effective radioisotope concentration than the human sodium iodide symporter gene in human and rodent cancer cells. Cancer Gene Therapy 10 14-22.

Katagiri H, Asano T, Ishihara H, Tsukuda K, Lin JL, Inukai K, Kikuchi M, Yazaki Y \& Oka Y 1992 Replacement of intracellular C-terminal domain of GLUT1 glucose transporter with that of GLUT2 increases Vmax and Km of transport activity. Journal of Biological Chemistry 267 22550-22555.

Kozak M 1997 Recognition of AUG and alternative initiator codons is augmented by $\mathrm{G}$ in position +4 but is not generally affected by the nucleotides in positions +5 and +6 . EMBO Journal $162482-2492$.

Kristensen AS, Larsen MB, Johnsen LB \& Wiborg O 2004 Mutational scanning of the human serotonin transporter reveals fast translocating serotonin transporter mutants. European Journal of Neuroscience 19 1513-1523.

Levy O, Dai G, Riedel C, Ginter CS, Paul EM, Lebowitz AN \& Carrasco N 1997 Characterization of the thyroid $\mathrm{Na}^{+} / \mathrm{I}^{-}$symporter with an antiCOOH terminus antibody. PNAS 94 5568-5573.

Levy O, Ginter CS, De la Vieja A, Levy D \& Carrasco N 1998 a Identification of a structural requirement for thyroid $\mathrm{Na}^{+} / \mathrm{I}^{-}$symporter (NIS) function from analysis of a mutation that causes human congenital hypothyroidism. FEBS Letters 429 36-40.

Levy O, De la Vieja A, Ginter CS, Riedel C, Dai G \& Carrasco N 1998 b $\mathrm{N}$-linked glycosylation of the thyroid $\mathrm{Na}^{+} / \mathrm{I}^{-}$symporter (NIS). Implications for its secondary structure model. Journal of Biological Chemistry 273 22657-22663.

Loland CJ, Norregaard L, Litman T \& Gether U 2002 Generation of an activating $\mathrm{Zn}(2+)$ switch in the dopamine transporter: mutation of an intracellular tyrosine constitutively alters the conformational equilibrium of the transport cycle. PNAS 99 1683-1688.

Magnon C, Opolon P, Ricard M, Connault E, Ardouin P, Galaup A, Metivier D, Bidart JM, Germain S, Perricaudet M et al. 2007 Radiation and inhibition of angiogenesis by canstatin synergize to induce HIF- $1 \alpha$ mediated tumor apoptotic switch. Journal of Clinical Investigation 117 1844-1855.

Mitrofanova E, Unfer R, Vahanian N \& Link C 2006 Rat sodium iodide symporter allows using lower dose of 131I for cancer therapy. Gene Therapy 13 1052-1056.

Mortensen OV, Kristensen AS \& Wiborg O 2001 Species-scanning mutagenesis of the serotonin transporter reveals residues essential in selective, high-affinity recognition of antidepressants. Journal of Neurochemistry 79 237-247.

Nagata K \& Hata Y 2006 Substrate specificity of a chimera made from Xenopus SGLT1-like protein and rabbit SGLT1. Biochimica et Biophysica Acta 1758 747-754

Panayiotidis MI, Bortner CD \& Cidlowski JA 2006 On the mechanism of ionic regulation of apoptosis: would the $\mathrm{Na}^{+} / \mathrm{K}^{+}$-ATPase please stand up? Acta Physiologica 187 205-215.

Perron B, Rodriguez AM, Leblanc G \& Pourcher T 2001 Cloning of the mouse sodium iodide symporter ( $\mathrm{mNIS}$ ) and its expression in the mammary gland and other tissues. Journal of Endocrinology 170 185-196.

Pohlenz J \& Refetoff S 1999 Mutations in the sodium/iodide symporter (NIS) gene as a cause for iodide transport defects and congenital hypothyroidism. Biochimie 81 469-476.

Smanik PA, Liu Q, Furminger TL, Ryu K, Xing S, Mazzaferri EL \& Jhiang SM 1996 Cloning of the human sodium iodide symporter. Biochemical and Biophysical Research Communications 226 339-345.

Szinnai G, Kosugi S, Derrien C, Lucidarme N, David V, Czernichow P \& Polak M 2006 Extending the clinical heterogeneity of iodide transport defect (ITD): a novel mutation R124H of the sodium/iodide symporter (NIS) gene and review of genotype-phenotype correlations in ITD. Journal of Clinical Endocrinology and Metabolism 91 1199-1204. 
Turner JR, Lencer WI, Carlson S \& Madara JL 1996 Carboxy-terminal vesicular stomatitis virus $\mathrm{G}$ protein-tagged intestinal $\mathrm{Na}^{+}$-dependent glucose cotransporter (SGLT1): maintenance of surface expression and global transport function with selective perturbation of transport kinetics and polarized expression. Journal of Biological Chemistry 271 7738-7744.

Weinman EJ, Cunningham R \& Shenolikar S 2005 NHERF and regulation of the renal sodium-hydrogen exchanger NHE3. Pflugers Archiv $\mathbf{4 5 0}$ 137-144.

Yernool D, Boudker O, Jin Y \& Gouaux E 2004 Structure of a glutamate transporter homologue from Pyrococcus horikoshii. Nature $\mathbf{4 3 1}$ 811-818.
Zhang Z, Liu YY \& Jhiang SM 2005 Cell surface targeting accounts for the difference in iodide uptake activity between human $\mathrm{Na}^{+} / \mathrm{I}^{-}$symporter and rat $\mathrm{Na}^{+} / \mathrm{I}^{-}$symporter. Journal of Clinical Endocrinology and Metabolism 90 6131-6140.

Received in final form 19 December 2007

Accepted 7 January 2008

Made available online as an Accepted Preprint 7 January 2008 